Valencia-Medina, M. \& Carmona Orantes, G. (2021). Análisis del impacto de un curso sobre autoconocimiento personal como medio de mejora profesional docente. Revista Electrónica Interuniversitaria de Formación del Profesorado, 24(3), 21-41.

DOI: https://doi.org/10.6018/reifop.458251

\title{
Análisis del impacto de un curso sobre autoconocimiento personal como medio de mejora profesional docente
}

\author{
Morelia Valencia-Medina, Gabriel Carmona Orantes \\ Universidad de Granada
}

\section{Resumen}

El desarrollo personal es un asunto de especial sensibilidad para quienes ejercen su profesión con seres humanos. El ámbito de la docencia permite, tal vez más que ningún otro, ser consciente de la relación entre la actuación propia y sus efectos. Por ello, se mantiene a lo largo de los años el interés por conocer sus distintos factores y aspectos.

Este estudio se propone conocer la percepción de profesionales de la Educación primaria y secundaria acerca de la relación entre autoconocimiento, mediante prácticas de autobservación, con el desarrollo personal y, a su vez, la incidencia de este último en la mejora profesional. Se basa en el análisis de contenido a partir de las reflexiones manifestadas por los participantes en una actividad formativo - educativa, consistente en la observación sostenida desde la atención hacia la interioridad personal, todos profesionales docentes. El estudio se ha realizado sobre una población de 37 participantes. Se ha usado una metodología cualitativa de carácter inductivo a partir de un instrumento, cuestionario, construido "ad hoc" y aplicado según modelo pretest-post test.

Para el análisis de datos se utilizó el programa ATLAS. Ti. del que se desprenden los siguientes resultados significativos: Los educadores y educadoras en un porcentaje del $71 \%$ manifiestan el interés de fortalecer la práctica de la autoobservación como vía de autoconocimiento y como objetivo para el desarrollo personal y mejora de la práctica profesional. Se constata que dicha acción proporciona una nueva mirada o comprensión del "sí mismo" y de la relación educadora con el alumnado.

\section{Palabras clave}

Educación; autoconocimiento; atención sostenida, auto observación, desarrollo personal, emoción.

\section{Contacto:}

Morelia Valencia-Medina, moreliavalenciam@gmail.com, Facultad de Ciencias de la Educación. Campus Universitario Cartuja s/n 18071 Granada, España

Este artículo aporta datos y resultados vinculados al curso "Desarrollo del desempeño docente: la atención y el autoconocimiento". Código: 201811GE022.

https://www.juntadeandalucia.es/educacion/secretariavirtual/consultaCEP/actividad/201811GE022/ 


\section{Analysis of the impact of a course on personal self-knowledge as a means of teacher professional improvement}

\section{Abstract}

Personal development is a sensitive matter for those who practice a profession interacting with people. Teaching allows, perhaps more than any other field, to be aware of the relationship between one's performance and its effects on students. Therefore, the interest in knowing its different factors and aspects is sustained over the years.

This study proposes to learn about the perception of primary and secondary education teachers about the relationship between self-knowledge, through self-observation practices, with personal development and, in turn, the incidence of the latter in professional improvement. The study is based on the content analysis of the thoughts manifested by the participants of a training-educational activity. This activity consisted of sustained observation from attention to personal interiority from all teaching professionals. The population of the study consists of 37 participants. An inductive qualitative methodology is used with an instrument, questionnaire, constructed "ad hoc" and it's applied according to the pretestposttest model.

The data analysis was performed using the ATLAS Ti program. After the analysis, the following significant results emerged: $71 \%$ of the teachers expressed interest in strengthening self-observation as a way of self-knowledge and as a goal for personal development and improvement of professional practice. It is found this action provides a new understanding of the "self" and the educational relationship teachers have with students.

\section{Keywords}

Education; self-knowledge; sustained attention, self-observation, professional development, emotion

\section{Introducción}

Desde hace algunos años se vienen realizando actividades y cursos para docentes desde la perspectiva del "desarrollo o crecimiento personal" para que, a su vez, incida en sus prácticas y enfoque educativo cotidiano.

El desarrollo personal es un concepto que se refiere a la actualización de todas las potencialidades emocionales e intelectuales de una persona, así como al desarrollo de sus habilidades, destrezas y talentos específicos. Es un concepto integrador, que supone el conocimiento de la persona acerca de sí misma y de su unicidad, el planteamiento de metas personales, el reconocimiento de los propios talentos y la formulación de objetivos coherentes con su sistema de valores. En este sentido, el desarrollo personal está íntimamente ligado al concepto de formación afectiva, valórica y de inteligencia emocional (Espinoza, 2015)

Estas propuestas, que son muy variadas, están basadas en experiencias que tienen que ver con el contenido de la perspectiva amplia del desarrollo personal y humano. A saber: Neuroeducación (Ocaña, 2015; Caballero, 2017), Inteligencia Emocional (Goleman, 2010; 2018; Gardner, 2020), Mindfulness (Germer, 2017; Moscoso, 2019) y Educación Emocional (Punset \& Bisquerra, 2016), (Bisquerra, 2018). 
El eneagrama permite a los docentes conocerse mejor a sí mismo como a sus estudiantes. De este modo, es una herramienta que permite introducir actividades de formación en el autoconocimiento para el docente (Naranjo, 2017; 2010) y actividades de reflexiones sobre el desarrollo de la personalidad en los estudiantes y como herramienta para la creación de grupos cooperativos en el aula (Ávila, 2015).

La utilización del eneagrama permite el autoconocimiento en un doble sentido. Por un lado, el conocimiento de las propias fortalezas y áreas de mejora a nivel personal y profesional. La experiencia práctica e integración de las virtudes es la prueba de la realización del equilibrio de la personalidad en el nivel humano, que tiene un sentido de responsabilidad interior (Baudino, 2017; 2014: 263).

Por otro lado, el eneagrama favorece el conocimiento de todos los miembros del equipo permitiendo resaltar y valorar las potencialidades de cada uno y ponerlas al servicio del trabajo grupal para mejorar procesos y resultados, así como adaptarse mejor a situaciones nuevas (Fontana Abad, Robledo Poma \& Juárez Pérez, 2011).

Desde la oferta de libre disposición de la Universidad de Granada, se han realizado desde el año 2017 cursos relacionados con la Educación y Consciencia y perspectiva Transpersonal de la Educación dirigidos al alumnado, futuros docentes en los que se han desarrollado aspectos necesarios como el "Autoconocimiento" y el desarrollo de la "Atención Integral".

La realización de estos cursos ha permitido generar inquietud en el estudiantado y ampliar su perspectiva en relación a los fines de la educación, en consonancia con el artículo 2 del BOE (2006): "El pleno desarrollo de la personalidad y de las capacidades de los alumnos" que a su vez concuerda con el artículo 27 de la Constitución, especialmente en el punto 2: "La educación tendrá por objeto el pleno desarrollo de la personalidad humana en el respeto a los principios democráticos de convivencia y a los derechos y libertades fundamentales".

El autoconocimiento es una competencia de especial valor en el proceso de construcción de la identidad profesional de educadores y educadoras en la medida que es "un proceso continuo y dinámico que, mediante el esfuerzo, la reflexión y la autoconciencia permite a la persona tener una percepción de "sí misma" incluyendo aspectos intelectuales, emocionales, valores éticos, capacidad de autonomía y deseos de autorrealización; a partir de la cual poder definir su identidad personal y desarrollar su personalidad" (Boixadós, Munté \& Pascual, Zueras, Matulic Domandzic y Báñez Tello, 2017). Además, participar en una comunidad docente de aprendizaje se reconoce como una práctica valiosa y necesaria para transformar las creencias y convicciones sobre el proceso de enseñanza (De Dios Alija, 2020).

Entendemos que quien es capaz de seguir y reconocer el valor de este proceso, no solo está capacitado, sino predispuesto a su promoción entre el alumnado. Por ello, constatamos que esta iniciativa generó interés y demanda entre el estudiantado del curso objeto de estudio en el presente artículo. $Y$ es por ello, que hasta la fecha se vienen realizando sucesivas ediciones de estos cursos.

Este hecho animó a extender la convocatoria a docentes en ejercicio a través del Centro del Profesorado (CEP) de Granada y fruto de esta experiencia surge el presente artículo, en el que se exponen y analizan:

1. El impacto del curso “Desarrollo del desempeño docente: La atención y el autoconocimiento" en la reelaboración de conceptos y vivencias relativas a la propia visión de Educación y finalidades de ésta. 
2. Cuál es el trabajo interno emocional, de habilidades sociales y de desarrollo profesional del educador y la educadora por medio del autoconocimiento.

Consideramos necesario dar cuenta de los resultados de estas experiencias, por cuanto puedan aportar al conocimiento acerca de cómo se produce el desarrollo profesional docente a partir del autoconocimiento.

Actualmente la educación, en cuanto acción para el desarrollo de la Personalidad, parece atravesar un estado de sobrevaloración de acciones pseudoterapeúticas dirigidas a los distintos aspectos constitutivos de la personalidad. La separación en compartimentos, mente - cuerpo - emociones no deja de ser una fractura de nuestra identidad y causa, por tanto, de alienación del ser humano. Es una separación formal con vistas al conocimiento del "objeto" por la vía analítica, pero en la "cultura de las prácticas educativas" se instala como método de intervención en la suposición de que las especializaciones tienen efecto en el segmento de personalidad al que se dirigen independientemente del resto.

Esta observación, nos induce a considerar necesaria una perspectiva de acción educativa reunificadora e integradora. Entendemos que a partir de la práctica del "autoconocimiento" el "desarrollo de la atención integral" fortalece a los educadores y educadoras en la doble necesidad insoslayable del "desarrollo personal" y en su desempeño profesional. Cuyo fin no es otro que contribuir a la "saludable y equilibrada" construcción de la personalidad de su alumnado. Diversos estudios han mostrado cómo la percepción que tiene el profesorado sobre su propia regulación emocional y la del alumnado incide en su labor profesional en el aula (Santander, Gaeta y Martínez-Otero, 2020). De hecho, son muchos los autores que defienden espacios de educación emocional en la formación docente que apunten a una relación con otros/as en la que "pensar en" pasa a complementarse con un "sentir con" (Silva-Peña y Paz-Maldonado, 2019).

Durante la práctica de los cursos anteriormente citados se han facilitado a modo de recursos para la sistematización del autoconocimiento, la técnica conocida como "Eneagrama" expresada como "un mapa que revela el mundo interno del hombre que se encuentra con la realidad de las leyes universales y externas donde nos encontramos", (Ouspensky citado en Aranda Pescador, 2013). Según este autor, el eneagrama nos permite reconocer las diferentes tendencias de la personalidad que hemos desarrollado, como también el reconocimiento de las cualidades y virtudes que cada ser humano ya trae en su propia "esencia".

Conscientes de la dificultad que implica describir y sobre todo dar cuenta de los alcances y posibilidades del "autoconocimiento humano" queremos afirmar, junto a Wilber (2013), que al igual que el conocimiento de la razón trasciende e incluye a lo sensorio-motriz, la contemplación trasciende a la razón. Y así como la razón no se puede reducir a operaciones sensorio-motrices, la contemplación no puede limitarse ni originarse en la razón. Por ello, queremos mostrar la educación como vía experiencial de acceso al conocimiento para el desarrollo de la auto-consciencia.

La consciencia, todo nuestro mundo interior de pensamientos, sentimientos, sueños, creencias, esperanzas, miedos, ideas, imágenes y demás, no se puede pesar ni medir, ni en modo alguno se puede tratar de la manera en que tratamos los objetos físicos (Lachman, 2016: 169).

La educación, a menudo, es tratada como una práctica instrumental para alcanzar un fin, pero, ¿qué ocurre cuando el fin es el desarrollo y crecimiento personal?; ¿cuáles son los caminos para la mejora? El trabajo que se expone se centra pues, en el análisis de una propuesta de acción educativa consistente en la observación dirigida (reflexión guiada) en 
torno a la atención hacia un "espacio interior" del propio educador o educadora. Acción que proporciona una nueva mirada hacia el "sí mismo" y hacia el alumnado.

Esta propuesta nace de una tendencia teórica "Pedagogía Transpersonal" (Santiago Martínez, 2010) que da justificación a una perspectiva Transpersonal de la Educación cuyo propósito es encauzar el fin de la educación hacia el conocimiento del "Sí mismo", destinado a la construcción de una personalidad integral plena (mente - cuerpo - emociones) elaborada a partir de la reflexión sobre las experiencias vitales auto-significativas.

Para ello, en la metodología seguida durante los cursos ya citados, se ha utilizado el cuerpo como punto de partida. Se ubica en el tiempo - espacio, "aquí y ahora" a través de movimientos especialmente diseñados, conocidos como ejercicios de disociación para el desarrollo de la atención, cuyo fin es el autoconocimiento.

Autoconocerse implica desarrollar la habilidad de dirigir la atención hacia el propio mundo interno y tomar conciencia de sí mismo, entender las emociones, su influencia en la experiencia y la conducta; y expresarlas de forma adecuada al contexto. Se relaciona con las actitudes y creencias del individuo sobre sí mismo, el aprecio por sí mismo y la confianza en su capacidad para lograr metas. El desarrollo del autoconocimiento es progresivo y precisa de la articulación de tres pilares fundamentales: la identidad y las metas, el desarrollo de la atención, y la conciencia de las emociones (Chernicoff Minsberg \& Rodríguez Morales, 2018); (Vidal, 2018).

De este modo se trata de llegar a un estado meditativo en el propio movimiento, como en la vida misma. Se pretende pues, generar estas experiencias desde el cuerpo en movimiento, crear así una visión del sujeto a través del esfuerzo consciente y la voluntad de sostenerse en el instante presente, uniendo lo mental (racionalidad consciente o estado de vigilia) con el corazón (conjunto organizado de emociones y sentimientos que mutuamente se refuerzan vinculándose al estado de conciencia del momento) (Ouspensky citado en Lachman, 2016: 87).

Por medio de estas prácticas se pueden estimular de manera efectiva y profunda la autoobservación y autoconocimiento a través de ello, la afirmación de lo que cada cual es como persona en relación con la propia personalidad e identidad individual y profesional. La consecuencia es, según Etievan (1996), sumergirse en un mundo con nuevas ideas sobre la naturaleza de la capacidad humana para aprender a enriquecer la vida, nutrirla y orientarla de manera creativa.

\section{Metodología}

Se ha empleado una metodología de carácter cualitativo, consistente en una prospección a partir de la aplicación de un cuestionario según modelo pretest y postest sobre una población de 37 docentes participantes en un curso para la mejora profesional mediante autoconocimiento a través de atención sostenida. Para ello, se elaboró "ad hoc" el instrumento de recogida de información a modo de cuestionario.

Dado que, por validez, de forma sencilla, entendemos que un instrumento es válido cuando mide lo que dice medir o, según Ander-Egg (1990: 87), "un cuestionario será válido si los datos obtenidos se ajustan a la realidad sin distorsión de los hechos". Seguimos el proceso siguiente: Acotar y formular el problema objeto de la investigación. Operacionalizar los aspectos del problema a investigar. Acotar los complejos temáticos en torno a los cuales agrupamos los ítems del cuestionario. Consultamos a 3 Expertos, profesores del Departamento de MIDE (Métodos de Investigación, Diagnóstico y Educación) de la 
Universidad de Granada. Decidimos establecer categorías de significado deducidas en función de la concordancia y similitud de las respuestas expresadas por los participantes. De este modo, apoyándonos en las respuestas dadas por los mismos en el cuestionario, deduciríamos las características de mayor peso que las identificaba. Por tanto, el cuestionario se construye a partir del conocimiento previo del colectivo sobre el que se va a intervenir. Por ello, las preguntas usan términos que tienen significados compartidos por los participantes, dado que se trata de profesorado de educación primaria y secundaria comprometido con la mejora de la práctica profesional.

Para ello, usamos las respuestas de los/as participantes, organizamos categorías que nos permiten valorar el paso, de la comprensión de la Educación como instrumento de transmisión sociocultural, a la significación de ésta como vía para el "autoconocimiento" y el desarrollo de la personalidad del ser humano como fin de la educación.

El citado instrumento consta de: pregunta inicial pretest y repetición de la misma pregunta post test. El tópico genérico sobre el que se organizan los ítems es: ¿Cuáles son los objetivos de la Educación?

El cuestionario aplicado en el pretest y postest es el siguiente:

\section{Cuestionario curso CEP NOV 2019}

1- ¿Que te motivó a realizar este curso?

2- ¿Qué entiendes por Educación?

3- ¿Cuáles son los objetivos de la educación? La pregunta tiene que ver con explicar qué se entiende por educación, cuál es nuestra experiencia de la misma, qué posibilidades tiene, y si es posible materializar un enfoque diferente.

4- ¿Podemos conocer la realidad?

5- ¿Es posible que haya otra forma de conocimiento que nos acerque a la realidad? Reflexiona.

6- ¿Cuál es el trabajo interno que tengo que hacer "YO" para ser el docente que quiero ser?

7- ¿He buscado alternativas, recursos, etc. para fortalecer ese docente que quiero ser?

8- ¿Qué entiendes por autoconocimiento? Defínelo con tus palabras.

9- En una escala de o a 10, ¿qué valor das al autoconocimiento en tu vida?

10- En una escala de o a 10, ¿qué valor das al autoconocimiento cómo docente?

11- ¿Qué entiendes por atención? Defínelo con tus palabras.

12- ¿Qué funciones cumple desde tu perspectiva la atención?

13- En el desarrollo profesional docente, ¿qué grado de incidencia tiene el Autoconocimiento? Valórelo en una escala de 1 a 10.

Educación: ¿Qué entiende por educación? y; ¿cuáles son los objetivos de la educación? Las preguntas tienen que ver con la clarificación conceptual y puesta en común de significados en torno a la noción de educación y sus objetivos.

Autoconocimiento: ¿Cuál es el trabajo interno que tengo que hacer "YO" para ser el Educador/a que quiero ser?, ¿He buscado alternativas, recursos, etc. para fortalecer ese Educador/a que quiero ser? ¿Qué entiendo por autoconocimiento? 
Las categorías de análisis que surgieron a partir de las respuestas son:

1. La Educación como transmisión de hábitos, valores, elementos culturales.

1.1 Como aprendizaje y fenómeno de conocimiento: Formación e instrucción.

1.2 La educación como aprendizaje para la socialización.

2. La Educación como desarrollo personal y autoconocimiento.

2.1 Como acción de desarrollo y crecimiento personal y toma de consciencia del individuo.

2.2 La educación como el arte de expresión humana, acompañando y guiando en el proceso de autoconocimiento.

2.3 La educación para el desarrollo integral del Ser humano.

3. El Autoconocimiento como fortalecimiento interno del educador/a.

3.1 Qué entiendo por autoconocimiento.

3.2 Interés de mejora del ser educador/a.

3.3 Conocimiento de sí mismo para la acción docente.

Se aplica a una población de 37 profesoras y profesores, docentes, maestras y maestros, por interés personal de los participantes en colaborar con la convocatoria realizada a través del Centro de profesorado de Granada "CEP" de diferentes centros educativos de la ciudad de Granada.

Para la generación y análisis de datos nos hemos basado en la información proporcionada a través de la aplicación del programa de análisis de datos cualitativos "ATLAS.ti". Los datos obtenidos se han sometido a un análisis categorial sobre las nociones anteriormente expuestas de donde deducimos la variación entre las percepciones iniciales y finales de los participantes.

\section{Resultados}

El total de respuestas emitidas en la administración inicial de la prueba es de 27 , equivalente a un $70 \%$ del total de participantes. De los cuales 24 son mujeres y 3 hombres. El $35 \%$ docentes de diplomatura de infantil y primaria; el $40 \%$ profesoras de educación secundaria; el $5 \%$ licenciados en pedagogía; 20\% otros profesionales de distintas ramas de la educación.

Se clasifican categoría y subcategoría o indicador obtenido por coincidencia semántica de las respuestas; el cálculo se basa en las respuestas dadas por los participantes, no por el número de participantes, ya que en algunos casos hay más o menos respuesta por pregunta.

\section{Análisis de las categorías según el pretest}

La categoría 1 "la educación como transmisión de hábitos, valores, elementos culturales" se construye, literalmente, con las 38 respuestas con mayor grado de coincidencia, de las cuales con el $68 \%$ se organiza la subcategoría 1.1 "La educación como aprendizaje y fenómeno de conocimiento, formación e instrucción”, con el 32\% restante organizamos la subcategoría 1.2, "La educación como aprendizaje para la socialización". 


\section{Figura 1.}

Red semántica. Pretest: La educación como transmisión de hábitos, valores y elementos culturales

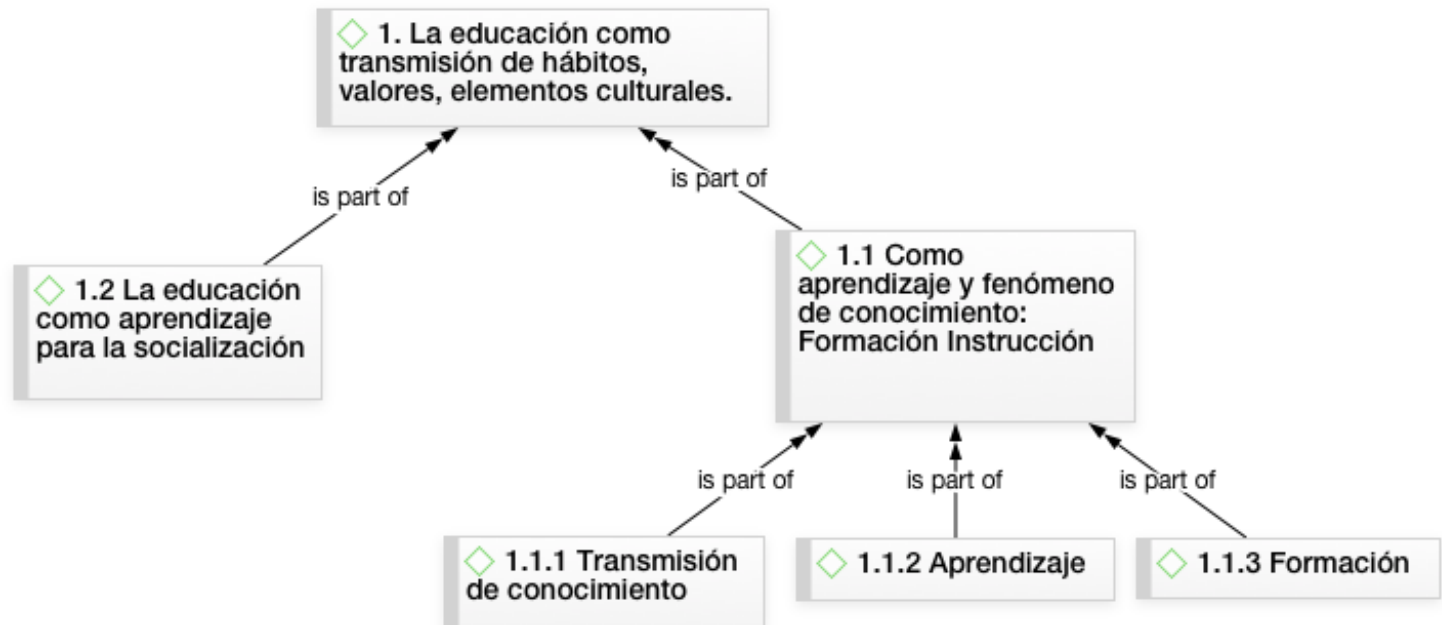

Una vez estructuradas las subcategorías dentro de la categoría 1, procedemos delimitar los indicadores que aparecen dentro de la subcategoría 1.1. Así, del 68\% de respuestas con las que se compuso, se deducen los indicadores 1.1.1 "Transmisión de conocimiento"; 47\% El indicador 1.1.2. "Aprendizaje" 39\% y, el indicador 1.1.3." Formación” 14\%.

\section{Figura 2.}

$1^{a}$ Categoría e indicadores: La educación como transmisión de hábitos, valores y elementos culturales

\section{CATEGORÍA: La Educación como transmisión de hábitos, valores y elementos culturales. \\ 1.1 Como aprendizaje y fenómeno de conocimiento: Formación e instrucción. \\ 1.2 La educación como aprendizaje para la socialización.}

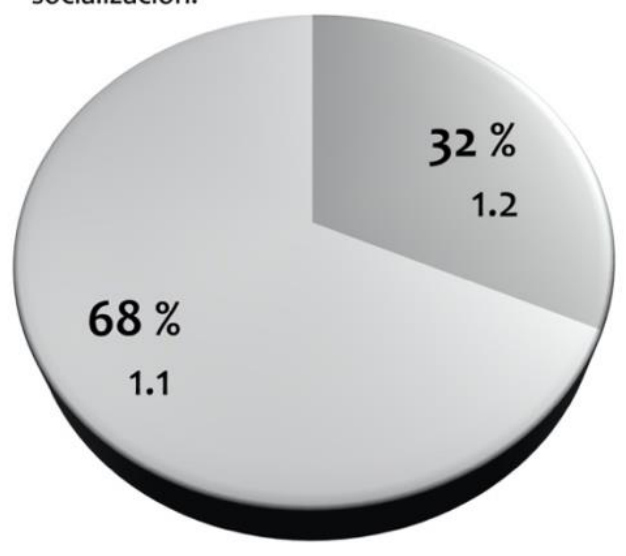

\section{Indicadores}

1.1.1 Transmisión de conocimiento.

1.1.2 Aprendizaje.

1.1.3 Formación.

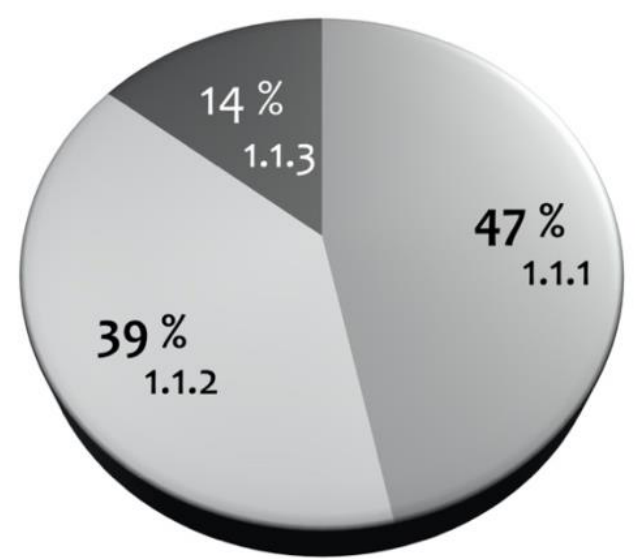

En esta primera categoría una amplia mayoría percibe la educación prioritariamente como un fenómeno de conocimiento, aprendizaje, formación e instrucción, repartido casi a partes iguales en transmisión de conocimiento, aprendizaje y formación. En segundo lugar, el otro tercio restante considera en primer lugar la educación como un aprendizaje para la socialización en sus diferentes aspectos, social, ético, cultural, valores, etc. 
Figura 3.

Red semántica. Pretest: La educación como desarrollo personal y autoconocimiento

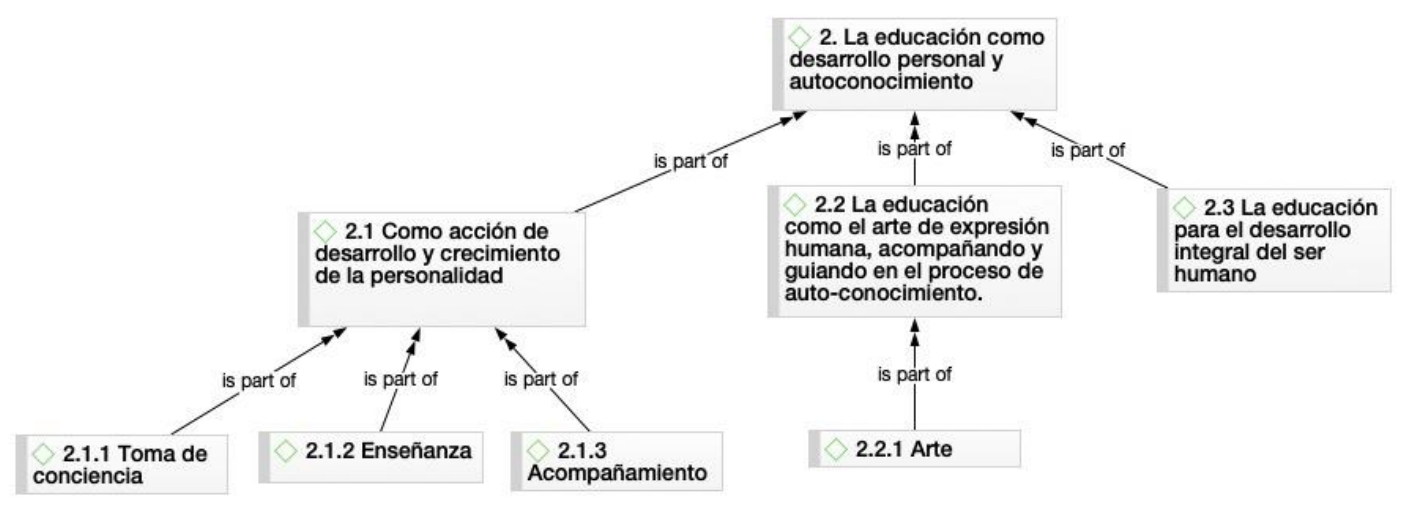

La categoría 2 "La educación como desarrollo personal y autoconocimiento" se construye a partir de 25 respuestas con el mayor grado de coincidencia, de las cuales con el $40 \%$ se construye la subcategoría 2.1 "Educación como acción para desarrollo de la personalidad" de la cual se deducen los indicadores 2.1.1 "Toma de conciencia", 30\% del total de la subcategoría. 2.1.2. "Enseñanza", 30\% del total de la subcategoría y 2.1.3. “Acompañamiento", 40\% de la subcategoría.

La subcategoría 2.2: "La educación como el arte de expresión humana acompañando y guiando en el proceso de autoconocimiento" se constituye con el $12 \%$ del total de respuestas agrupadas en la categoría 2.

La subcategoría 2.3: "La educación para el desarrollo integral del ser humano" se construye con el $48 \%$ de las respuestas habidas en la categoría 2.

\section{Figura 4.}

$2^{a}$ Categoría e indicadores: La educación como desarrollo personal y autoconocimiento

\section{CATEGORÍA: La Educación como desarrollo personal y} autoconocimiento

2.1 Como acción de desarrollo y crecimiento de la personalidad.

- 2.2 La educación como el arte de expresión humana acompañando y guiando en el proceso de autoconocimiento.

2.3 La educación para el desarrollo integral del Ser humano.
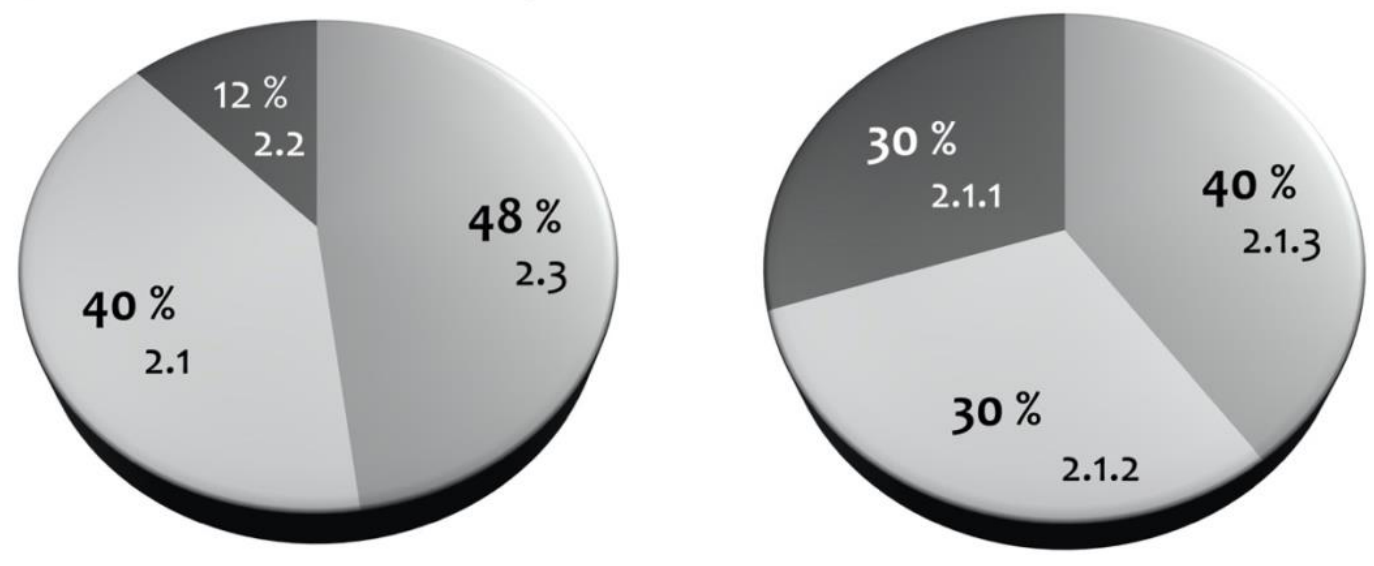
Se recogen literalmente las 25 respuestas con mayor grado de coincidencia para configurar esta categoría 2, de las cuales, a su vez, dentro de esta subcategoría, un 30\% corresponde los indicadores: 2.1.1 el 30\%; el 2.1.2 el 30\%; y a la 2.1.3 el 40\%. Así, la subcategoría 2.2 tiene el 12\% de las respuestas y la subcategoría 2.3 el $48 \%$ restante.

En el segundo epígrafe o categoría relacionado con la Educación como desarrollo personal y autoconocimiento, la educación para el desarrollo integral del ser humano es la subcategoría que agrupa casi la mitad de las respuestas. Muy parecido al porcentaje de las respuestas que consideran prioritaria la toma de consciencia del individuo para la educación como crecimiento personal y haciendo énfasis, en este caso, en el concepto de acompañamiento, pero también de forma significativa, aunque en menor medida, en el sistema de enseñanza y el proceso específico de toma de conciencia durante el aprendizaje.

Finalmente, para un pequeño porcentaje, la Educación es un arte de la expresión humana que hay que guiar y acompañar para el autoconocimiento.

Figura 5.

Red semántica. Pretest: El autoconocimiento como fortalecimiento interno del educador

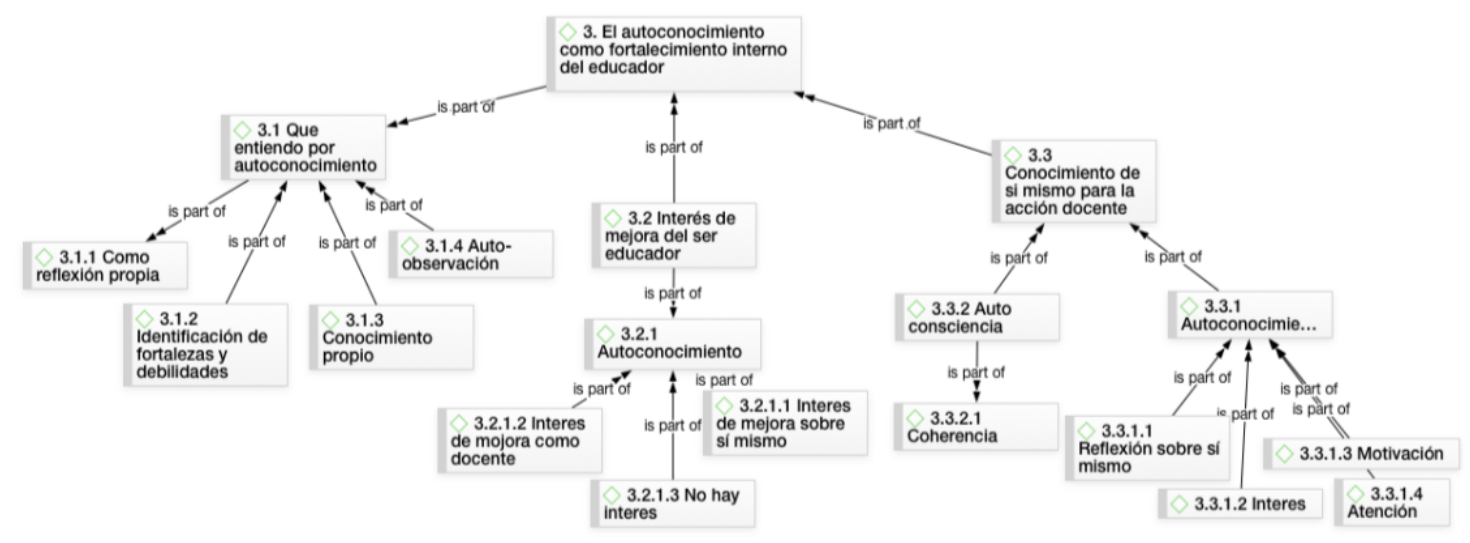

La categoría 3. "El autoconocimiento como fortalecimiento interno del educador". Se construye a partir de las 71 respuestas con mayor grado de coincidencia, de las cuales el 36\% se refiere a la subcategoría 3.1 "Qué entiendo por autoconocimiento" dentro de la cual tenemos la siguiente distribución: el 11\% correspondiente al indicador 3.1.1. "como reflexión propia"; el 19\% corresponde al 3.1.2 "identificación de fortalezas y debilidades"; el 54\% al 3.1.3 "conocimiento propio" y el 16 \% al 3.1.4, autoobservación.

En la subcategoría 3.2 "Interés de mejora del ser educador" tenemos un 34\% de respuestas, todas agrupadas en el indicador 3.2.1 "Autoconocimiento" en el cual hay tres subindicadores. El primero 3.2.1.1 "interés de mejora sobre el sí mismo" con el 46\%; el segundo 3.2.1.2 "Interés de mejora como docente" con el $38 \%$ y el tercero 3.2.1.3 "No hay interés" con el $4 \%$. El 12\% restante de las respuestas son agrupables directamente al indicador 3.2.1 de autoconocimiento. 
Figura 6.

$3^{a}$ Categoría e indicadores: El autoconocimiento como fortalecimiento interno del educador. Qué entiendo por autoconocimiento.

\section{CATEGORÍA: El Autoconocimiento como fortalecimiento interno del educador. \\ 3.1 Que entiendo por autoconocimiento. \\ 3.2 Interés de mejora del ser educador. \\ 3.3 Conocimiento de si mismo para la acción docente.}

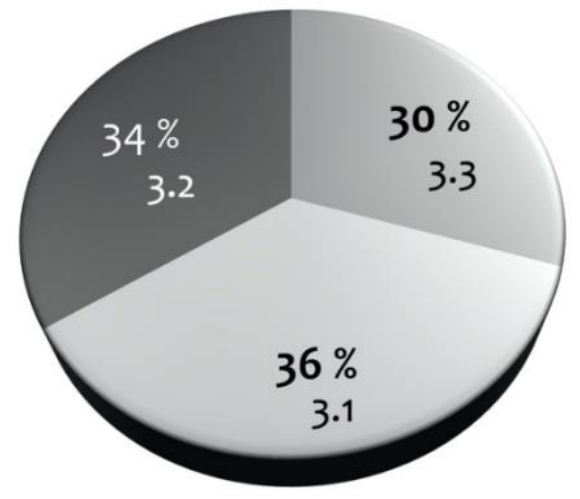

\section{Indicadores}

3.1 Que entiendo por autoconocimiento.

3.1.1 Como reflexión propia.

3.1.2 Identificación de fortalezas y debilidades.

3.1.3 Conocimiento propio.

3.1.4 Auto-observación.

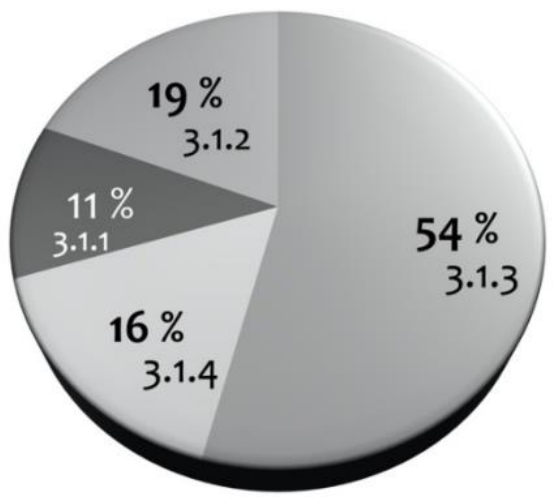

Figura 7.

$3^{a}$ Categoría e indicadores: El autoconocimiento como fortalecimiento interno del educador. Interés de mejora del ser educador. Conocimiento de sí mismo para la acción docente.

\subsection{Interés de mejora del ser educador.}

3.2.1 Autoconocimiento.

3.2.1.1 Interés de mejora sobre sí mismo.

3.2.1.2 Interés de mejora como docente.

3.2.1.3 No hay interés.

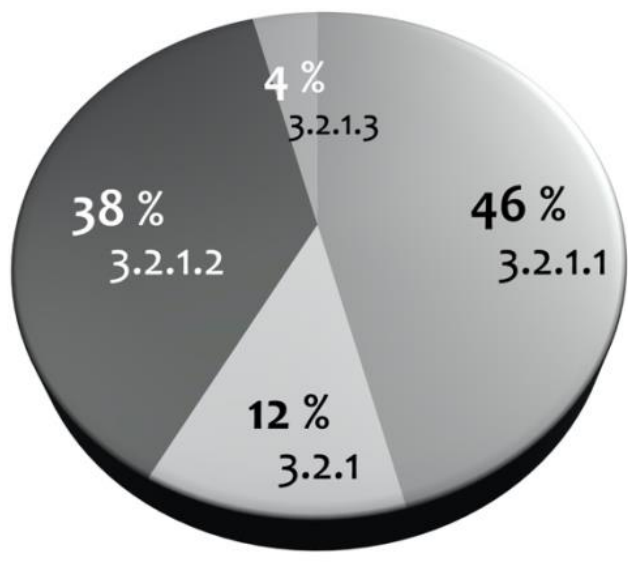

3.3 Conocimiento de si mismo para la acción docente. 3.3.1 Autoconocimiento.

3.3.2 Autoconsciencia.

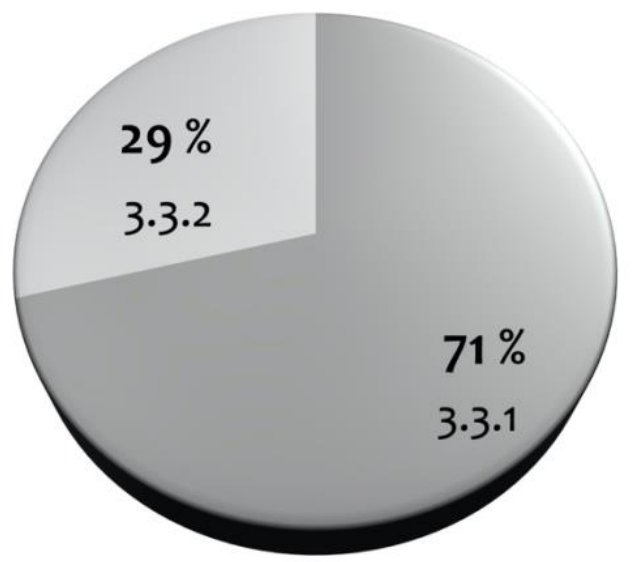

En la subcategoría 3.3, "Conocimiento de sí mismo para la acción docente" tenemos el 30\% de respuestas, dentro de las cuales tenemos el indicador 3.3.1 "Autoconocimiento" con 71\% de respuestas y el 3.3.2 "Autoconsciencia" con el 29\% de respuestas. Dentro del indicador 3.3.1 tenemos el 3.3.1.1 "Reflexión sobre sí mismo" con el 56\% de respuestas, el 3.3.1.2 
"Interés" con el 26\% de respuestas, el 3.3.1.3 "Motivación" con el 6\% de respuestas y el 3.3.1.4 "Atención" con el 12\% de respuestas.

\section{Figura 8.}

$3^{a}$ Categoría e indicadores: El autoconocimiento como fortalecimiento interno del educador
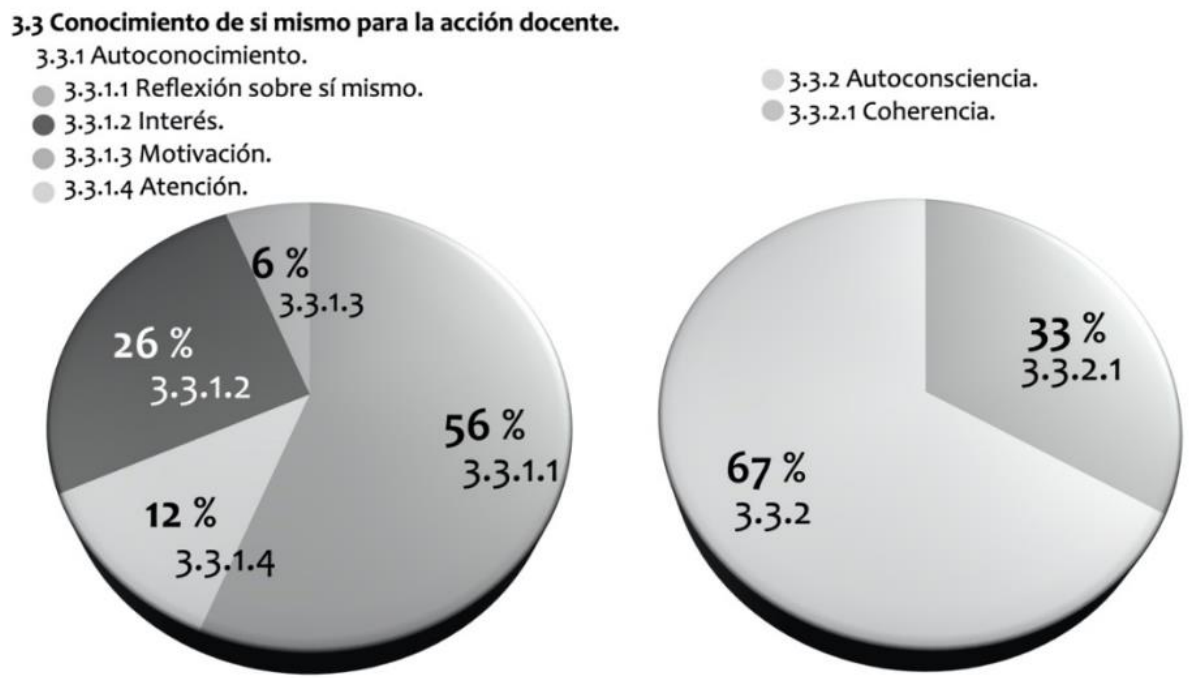

Dentro del indicador 3.3.2 "Autoconsciencia" tenemos el 3.3.2.1 "Coherencia" con el 33\% de respuestas y $67 \%$ restante de respuestas son agrupables directamente en el indicador 3.3.2. Resulta especialmente llamativo la agrupación de las respuestas respecto al autoconocimiento como fortalecimiento interno del educador, en tres tercios prácticamente similares en porcentaje.

El primero entiende mayoritariamente el autoconocimiento como conocimiento propio y en menor medida como autoobservación o reflexión propia. Un pequeño porcentaje lo enfoca en la identificación de las fortalezas y debilidades propias. El segundo tercio que tiene que ver con la mejora del ser educador, la mayoría se enfoca en la acción de mejora sobre sí mismo, como persona o específicamente sobre la mejora de su acción docente; un pequeño grupo sigue realizando énfasis en que la mejora se realiza directamente a través del autoconocimiento. Se detecta un mínimo porcentaje que manifiesta no tener interés de mejora. En tercer lugar, relacionado con el epígrafe o categoría, el autoconocimiento como fortalecimiento interno del educador un $67 \%$ le da importancia a la autoconsciencia del educador y un $33 \%$ enfatiza además la coherencia del mismo.

\section{Análisis de las categorías según el postest}

Se recogen literalmente 24 respuestas, con mayor grado de coincidencia en esta categoría 4 "La educación como transmisión de hábitos, valores, elementos culturales" de las cuales en la subcategoría 4.1 "como aprendizaje y fenómeno de conocimiento, formación e instrucción" se agrupa el 58 \% de las respuestas, dentro de la cual el indicador 4.1.1 "Transmisión de conocimiento" tiene el 7\% el 4.1.2 "Aprendizaje" el 14\% el 4.1.3" Formación" tiene el $44 \%$. $Y$ un $35 \%$ se encuentran agrupados directamente en el epígrafe de la subcategoría 4.1 
Figura 9:

Red semántica. Postest: La educación como transmisión de hábitos, valores y elementos culturales

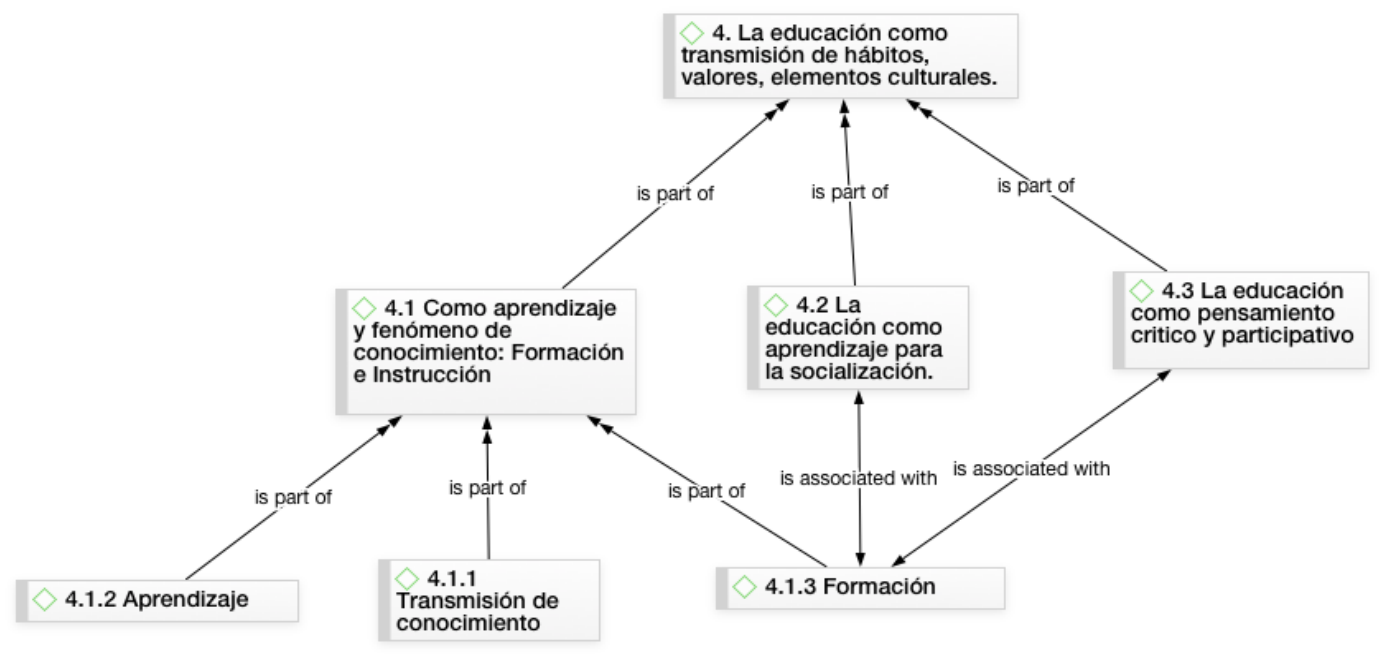

El resto de las respuestas está agrupado en la subcategoría 4.2 "la educación como aprendizaje para la socialización ", tiene el $25 \%$ de las respuestas, y la 4.3 "La educación como pensamiento crítico y participativo” agrupa el $17 \%$ restante de las respuestas.

\section{Figura 10.}

$4^{a}$ Categoría e indicadores: La educación como transmisión de hábitos, valores y elementos culturales

\section{CATEGORíA: La Educación como transmisión de} hábitos, valores y elementos culturales.

4.1 Como aprendizaje y fenómeno de conocimiento: Formación e instrucción.

4.2 La educación como aprendizaje para la socialización.

4.3 La educación como pensamiento crítico y participativo.

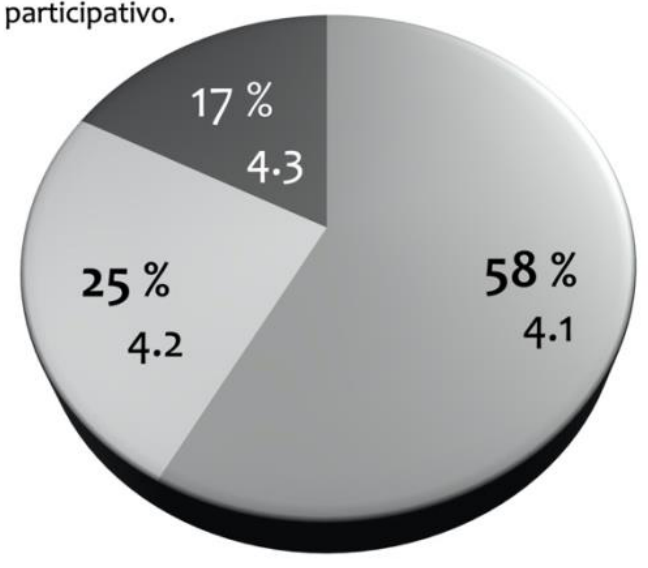

\section{Indicadores}

4.1 Como aprendizaje y fenómeno de conocimiento: Formación e instrucción.

4.1.1 Transmisión de conocimiento.

4.1.2 Aprendizaje.

4.1.3 Formación.

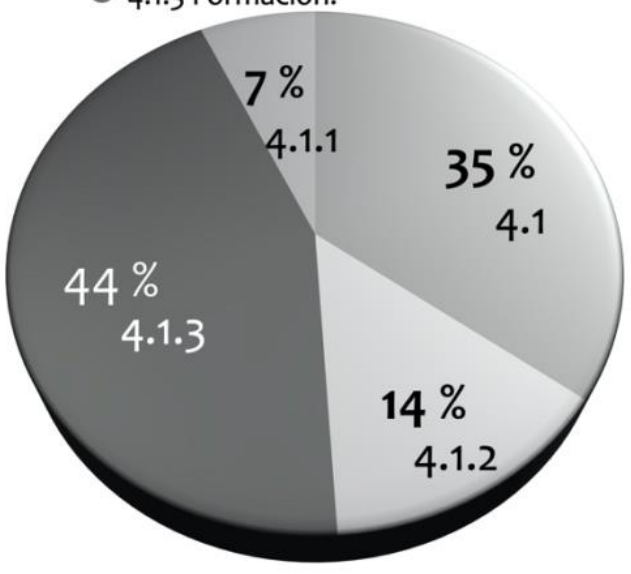

Las respuestas agrupadas como primera categoría en la fase del post test durante la sesión final del curso, mayoritariamente, consideran la educación como aprendizaje y fenómeno de conocimiento, casi la mitad de las respuestas enfatiza el proceso de formación global e 
integral del individuo. En segundo lugar, la cuarta parte de las respuestas recogidas coinciden en una visión de la educación como acción encaminada a aspectos de desarrollo social, ciudadano, etc. Además, una cantidad minoritaria de respuestas recogidas en el postest generan una nueva categoría que agrupa un $17 \%$ de respuestas donde se manifiesta una visión de la educación como pensamiento crítico, liberador y participativo.

Un 68\%, según reflejan las respuestas del pretest sobre "Qué se entiende por educación", coincide en percibir la educación prioritariamente como un fenómeno de adquisición de conocimientos, aprendizaje, formación e instrucción, de hábitos y destrezas donde se facilitan herramientas para el desenvolvimiento de la vida socioeconómica, que claramente alude a una orientación instrumental de la educación.

Este porcentaje vemos que se reduce a un $58 \%$ en el post test, es muy parecido en su intención educativa, pero a nivel interno cambia el sentido de cómo conseguirlo, por ejemplo: en el pretest a la formación se le daba solo un interés del $14 \%$ mientras que a la mera transmisión del conocimiento un $47 \%$ o al acto de aprendizaje un 39\%. Estos datos se invierten en el post test donde se enfatiza la formación con un $44 \%$ mientras que el aprendizaje o transmisión del conocimiento baja a un $14 \%$ y $7 \%$ respectivamente.

El resto de porcentaje están relacionados con la educación como socialización que se mantiene en forma parecida en el postest y en el pre test, pero con la salvedad de que en el postest este aspecto socializador da lugar a una nueva subcategoría que ve la educación como pensamiento crítico y participativo con un $17 \%$.

Figura 11.

Red semántica. Postest: La educación como desarrollo personal y autoconocimiento

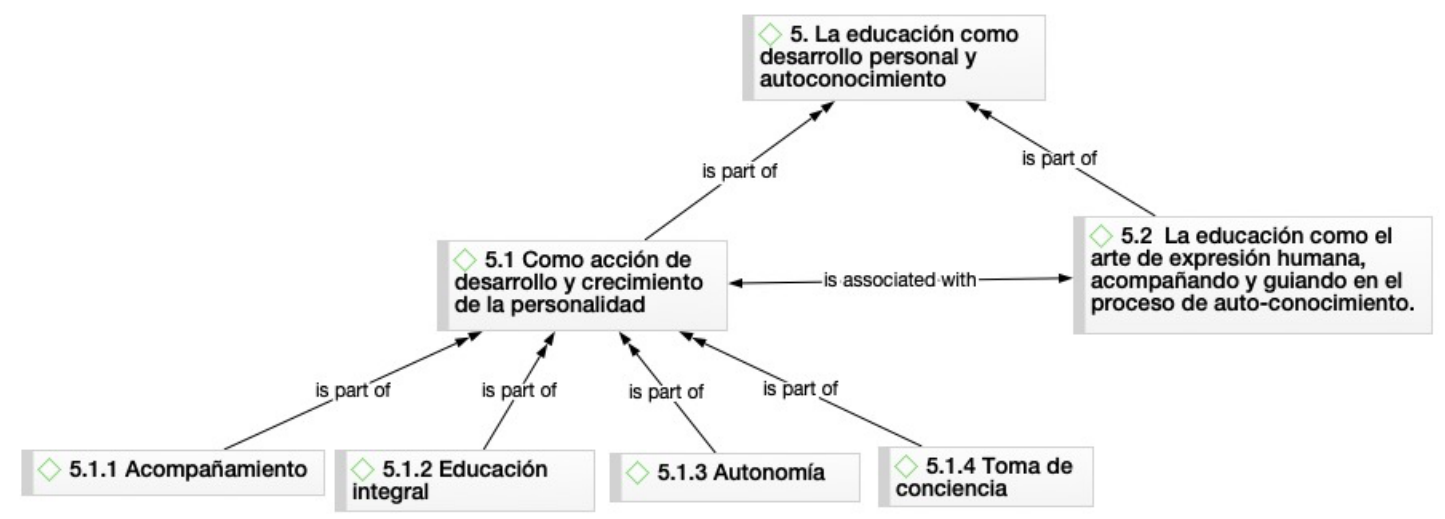

Se recogen literalmente 21 respuestas con mayor grado de coincidencia en esta categoría 5 "La educación como desarrollo personal y autoconocimiento" de las cuales, la subcategoría 5.1 "Como acción de desarrollo y crecimiento de la personalidad" agrupa el 85\% de las respuestas, dentro de la cual el indicador 5.1.1 "Acompañamiento" tiene el 5\%, el 5.1.2 "Educación integral" el 63\%, el 5.1.3"Autonomía" tiene el 10 \% y el 5.1.4 "Toma de conciencia" tiene el $5 \%$ y un $17 \%$ que se encuentran agrupados directamente en el epígrafe de la sub categoría 5.1; la subcategoría 5.2 "La educación como el arte de expresión humana acompañando y guiando en el proceso de autoconocimiento" tiene el 15\% de las respuestas. 
Figura 12.

$5^{a}$ Categoría e indicadores: La educación como desarrollo personal y autoconocimiento

5. CATEGORíA: La Educación como desarrollo personal y autoconocimiento

5.1 Como acción de desarrollo y crecimiento de la personalidad.

5.2 La educación como el arte de expresión humana acompañando y guiando en el proceso de autoconocimiento.
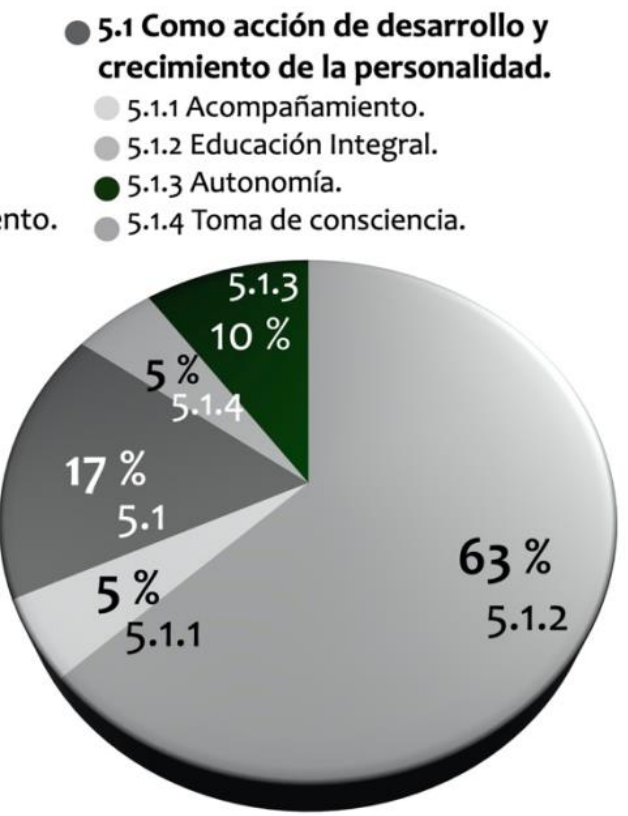

En torno a la categoría 5, la mayoría de las respuestas coinciden en ver el desarrollo personal como fin de la educación mediante acciones de desarrollo y crecimiento de la personalidad, de forma que se observa en el postest con un $63 \%$ de estas respuestas, que ven en la educación integral la forma más adecuada de conseguir este objetivo. Otros aspectos minoritarios para conseguir este objetivo que aparece en el postest son promover la autonomía del individuo o bien su toma de conciencia durante el proceso educativo.

En segundo lugar, un pequeño porcentaje de respuesta, 15\%, considera fundamental el proceso de guía y acompañamiento del alumnado en este proceso.

Al comparar el post test con el pretest vemos que se ha duplicado (del $40 \%$ al $85 \%$ ) las respuestas que consideran prioritaria la educación como crecimiento personal del individuo y desarrollo de su personalidad, así como la necesidad de una acción educativa activa para el desarrollo integral para el ser humano. Para este objetivo en el post test vemos que aparece el indicador de educación integral con gran importancia $63 \%$ y que en el pretest era solo enseñanza con un 12\%. En el concepto integral de la educación que aparece en el post test se incluyen los conceptos de acompañamiento y toma de consciencia que de forma independiente aparecen con valores elevados en los indicadores del pretest, por lo que en el post test pierden importancia como parámetros independientes al estar tácitamente incluidos en el indicador 5.1.2 educación integral.

Por otro lado, la visión de la educación como el arte de expresión humana y participación del arte en general en el proceso de autoconocimiento se mantiene en un pequeño porcentaje, pero significativo tanto en el pretest $12 \%$ como en el post test $15 \%$. 
Figura 13:

Red semántica: Postest: El conocimiento como fortalecimiento interno del educador

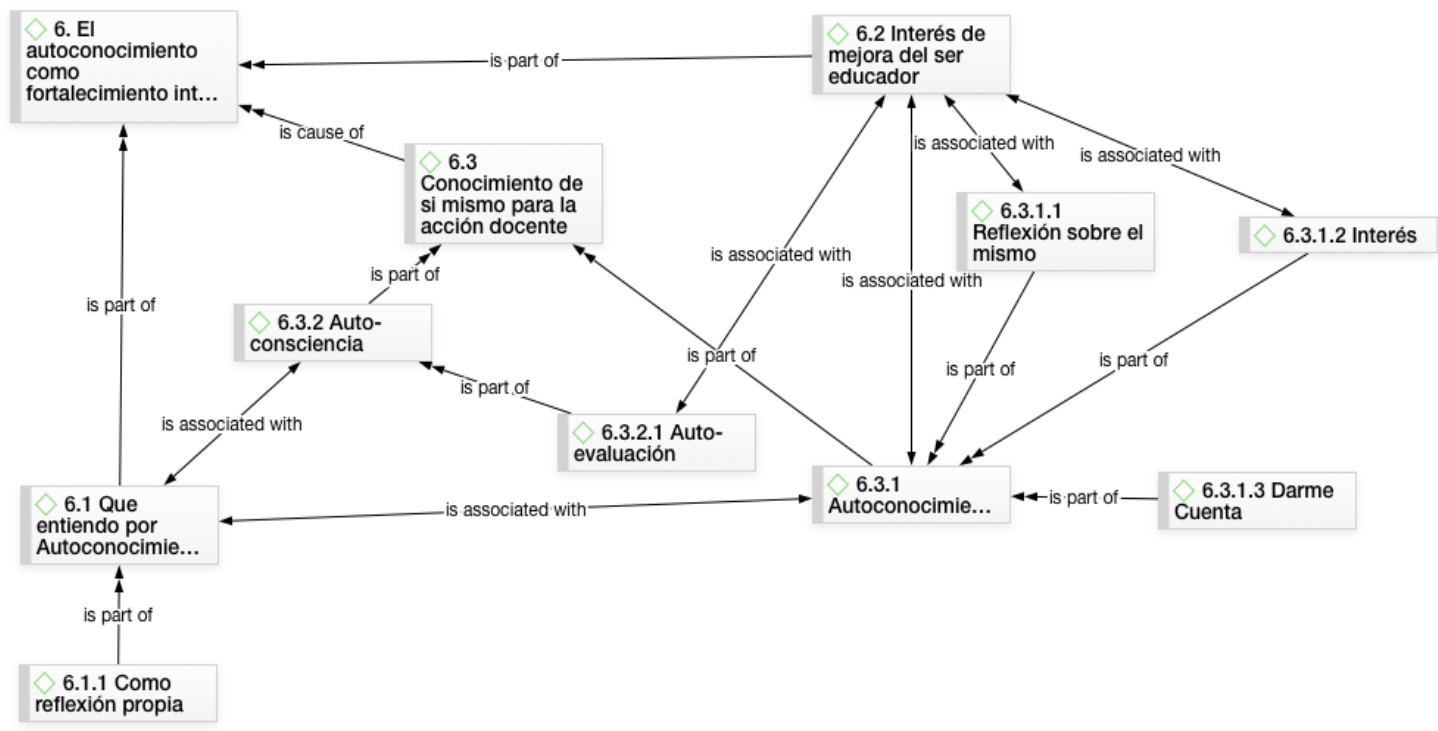

Para configurar la categoría 6 "Autoconocimiento como fortalecimiento de ser educador/a" se recogen en su literalidad las 58 respuestas que presentan el mayor grado de coincidencia. De entre estas obtenemos la subcategoría 6.1 "Qué entiendo por autoconocimiento" que agrupa el $29 \%$ de las respuestas. A su vez, dentro de este porcentaje se obtiene el indicador 6.1.1 "Como reflexión propia" con el $6 \%$ del antedicho porcentaje que constituye la subcategoría 6.1

Del mismo modo se configura la subcategoría 6.2 "Interés del ser educador" con un $48 \%$ de coincidencia del total de las respuestas literales. La categoría 6.3 "Conocimiento de sí mismo para la acción docente" se confecciona con el $23 \%$ de coincidencias de las respuestas totales.

Mientras que la subcategoría 6.3.1 "Autoconocimiento" obtiene el $25 \%$ del total de coincidencias, incluyendo en este porcentaje la "Reflexión sobre sí" (6.3.1.1), "El interés" (6.3.1.2) y "El darme cuenta" (6.3.1.3) y la subcategoría, 6.3.2 "Autoconsciencia", el $75 \%$ restante incluyendo también la "Autoevaluación" (6.3.2.1). Observamos que la mitad del porcentaje total de las respuestas son expresiones diversas y expresan el interés de mejora para "ser educador/a".

El resto se divide en dos mitades casi iguales, una donde se destaca la importancia de que la vía para el desarrollo interno del educador/a es el autoconocimiento como sujeto de su comportamiento ético y como persona, lo cual se manifestará en todos sus aspectos vitales, mientras que el otro grupo manifiesta interés en el autoconocimiento específicamente asociado a la acción docente.

Significativamente vemos que el interés de mejora del ser educador aumenta desde el $34 \%$ del pretest al $48 \%$ del post test. En el ámbito del conocimiento del sí mismo para la acción docente se incrementa en el post test la importancia que se le da a la autoconsciencia (75\%) con respecto al pretest (29\%), mientras que el autoconocimiento se reduce dividiéndose en conceptos como reflexión sobre sí mismo, darme cuenta, atención, interés, sumando un $25 \%$ en el post test, mientras que en el pretest era un $71 \%$ entendiendo mayoritariamente el $56 \%$ 
el autoconocimiento como reflexión del sí mismo. Como podemos observar por un camino u otro el autoconocimiento y la autoconsciencia se captan como importantes en un trabajo sobre el propio docente.

Figura 14.

$6^{a}$ Categoría e indicadores: El autoconocimiento como fortalecimiento interno del educador

6.CATEGORÍA: El Autoconocimiento como fortalecimiento interno del educador.

6.1 Que entiendo por autoconocimiento.

6.2 Interés de mejora del ser educador.

6.3 Conocimiento de si mismo para la acción docente.

6.3.1 Autoconocimiento.

6.3.2 Autoconsciencia
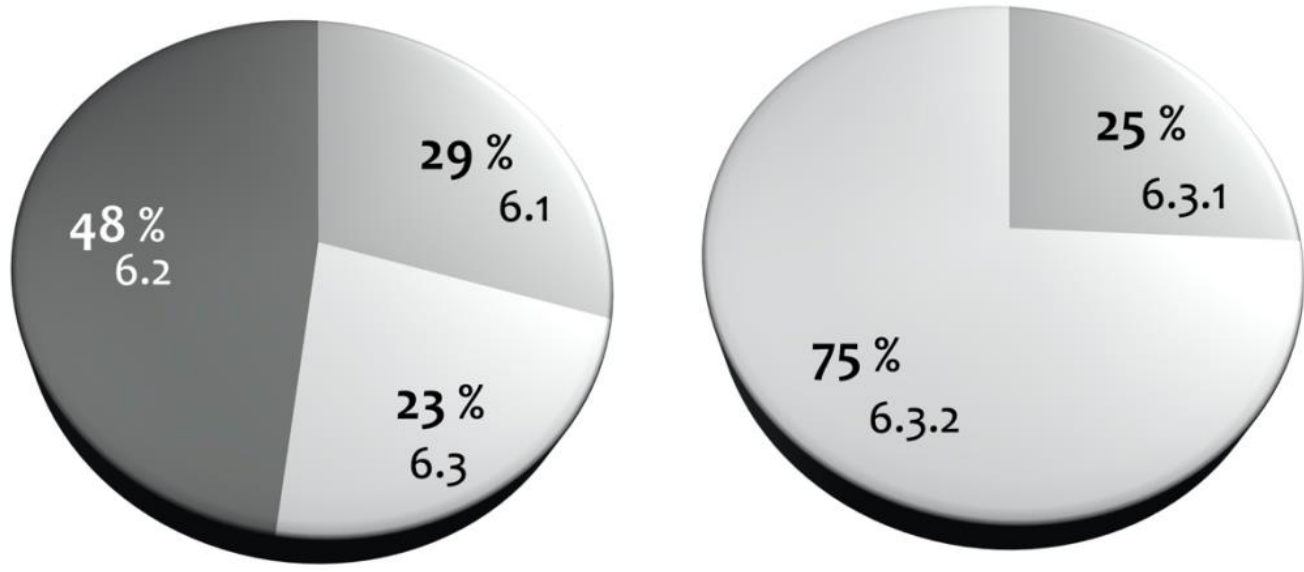

\section{Discusión y conclusiones}

El recuento de respuestas obtenidas en la fase pretest nos muestra la visión que los participantes tienen de la educación al inicio del curso. Caracterizada por la perspectiva de acción dirigida a la transmisión de hábitos, valores y elementos culturales.

En primer lugar, una amplia mayoría según refleja las respuestas del pretest sobre "Qué se entiende por educación", coincide en percibir la educación prioritariamente como un fenómeno de adquisición de conocimientos, aprendizaje, formación e instrucción, de hábitos y destrezas donde se facilitan herramientas para el desenvolvimiento de la vida socio económica, que claramente alude a una orientación instrumental de la educación.

En segundo lugar, una cantidad significativa de respuestas consideran prioritaria la educación como crecimiento personal del individuo y desarrollo de su personalidad, así como de la necesidad de una acción educativa activa para el desarrollo integral para el ser humano. Un porcentaje menor percibe la educación como fenómeno social y como el proceso de aprendizaje para facilitar la socialización en cuanto meta de la integración social de los individuos en el "corpus" social y político.

Sin embargo, las expresiones manifestadas en la fase post test, al finalizar el curso, son especialmente llamativas por la alta agrupación de respuestas respecto al interés de búsqueda de estrategias para el conocimiento de sí, recurriendo a experiencias de nuevas alternativas a través de la meditación, yoga, Mindfulness, cursos de neuroeducación, etc. que 
faciliten sus procesos de observación, identificación de fortalezas y debilidades, a través de la introspección para conocimiento del sí mismo.

Otro porcentaje apunta a la mejora como persona o específicamente sobre la mejora de su acción docente ya que éstas consideran a la educación como aprendizaje y fenómeno de conocimiento. Se hace énfasis en el proceso de formación global e integral, no solamente en conocimiento, sino también en la moral, afectividad, motivación e inclusión social del individuo. Se observa un porcentaje menor que manifiesta entender la educación como "pensamiento crítico, liberador y creativo. Así mismo, ofrece los ámbitos y las oportunidades para que cada ser humano se pueda desarrollar, hacer personas libres y conscientes".

Referente a la educación como desarrollo personal y autoconocimiento, las respuestas muestran que el desarrollo personal a través de la educación es una acción de desarrollo y crecimiento de la personalidad del docente. De forma que se observa en el postest un gran porcentaje de estas respuestas que ven en la educación integral la forma más adecuada de conseguir "sacar de dentro lo mejor de cada persona", sus dones, sus virtudes y potenciarlo para que pueda enfocar su propósito de "ser" y "hacer en la vida".

La amplia mayoría de los participantes demanda la importancia del fortalecimiento interno del individuo a través del auto conocimiento, lo cual se manifestará en todos sus aspectos vitales y sobre todo en el "ser educador" para poder ser guía de su alumnado.

Por último, a tenor de lo expuesto se constata una clara diferencia entre la visión manifestada por los participantes acerca de la práctica de la Educación y su finalidad, en la fase inicial del curso y la expresada al final. Cabe pensar en que las prácticas, metodología y contenidos del curso han contribuido a este efecto.

El objetivo es que el docente reflexione sobre la noción de educación y que se produzca en él una aclaración de este concepto que lo pueda llevar a un replanteamiento que lo lleve a una perspectiva más amplia de la acción educativa; esto se alcanza, como se pone de manifiesto, en sus respuestas, donde vemos que se consigue en distintos grados, pero siempre en la dirección de una mayor concienciación de la importancia, naturaleza y repercusiones de educar.

De igual modo, el otro propósito principal de situar el autoconocimiento y por ende la autoconsciencia como fundamento educativo, se obtiene con la experiencia práctica a lo largo del curso sobre la disociación de su propio cuerpo y la observación durante esta actividad de sus procesos mentales y emocionales, con la doble repercusión que esta experiencia tiene para ellos como persona y docente y posterior proyección en los educandos.

La idea previa, expresada por los docentes, sobre educación, es que básicamente se trata de una acción de transmisión para la adquisición, por parte de las nuevas generaciones, de valores, patrones socioculturales y habilidades para el desempeño socioeconómico. Resulta particularmente llamativo este extremo por cuanto intuimos que es extrapolable al conjunto de la sociedad. Sin embargo, y al mismo tiempo, se confía a la acción educativa la responsabilidad para producir la adaptación a los cambios sociales y el comportamiento moral consecuente.

Durante el curso se muestra que la Educación, tal como señala Sotelo (1995) requiere de un "referente humano", un modelo antropológico, pues la educación es un proceso social de mayor complejidad que la socialización y la instrucción, aunque participa de los rasgos de ambas. Se distingue de la instrucción o de la socialización en que persigue la realización de un tipo ideal de sujeto humano. La educación tiene una dimensión normativa y necesita, por tanto, una jerarquía de valores. No se puede educar sin poseer previamente una visión del 
modelo de ser humano, como paradigma que hay que alcanzar. Así entendida la educación, necesita de una cosmovisión, de unas creencias, que bien pueden aportar la antropología filosófica o las religiones, para definir el tipo humano que se desea alcanzar.

La libertad se revela de un lado, como noción clave que explica al ser humano (decisiva, para entenderlo como sujeto moral y para dar cuenta de la convivencia social y política) y del otro, el concepto mismo de libertad cambia sustancialmente su contenido, pues de entenderse como libre albedrío, pasa a concebirse como autonomía del sujeto. Esta doble conceptualización modifica sustancialmente la idea de educación por cuanto coloca en el fin de esta el logro de la autonomía del sujeto en cuanto capacidad de autogobierno y esta solo se puede alcanzar desde el autoconocimiento y la libertad.

La educación en esta concepción no parte de un paradigma externo al que hay que adaptar al individuo, sino más bien es un proceso de eliminación de los factores externos, que impiden que cada uno llegue a ser el que realmente es. No se trata tanto de dirigir, de encauzar, como de promover el conocer-se y dejar crecer. Educar es protegernos de la socialización para abrirnos a la comprensión y obediencia de la voluntad general. La enseñanza para la libertad, y desde la libertad, supone una educación crítica, consigo mismo y con el mundo que nos rodea. Desde ahí, importa "vivir el no-saber como oportunidad, pasando por el atreverse a pensar con libertad pese al dolor de la lucidez" (Caparrós y Sierra, 2019: 191).

De la idea de libertad, soporte fundamental de la educación, se derivan otras dos igualmente relevantes; una la de individualidad, noción por la cual consideramos que cada cual es distinto y único, lo que hace necesario adecuar el proceso educativo a la individualidad propia de cada educando. Y otra la de actividad, papel que corresponde al educando en cuanto protagonista del proceso educativo, en el sentido de que sólo cabe educarse ejerciendo activamente las facultades del cuerpo y del espíritu, se aprende a pensar pensando, o a ser autónomo ejerciendo la autonomía, y no a través de un discurso que explique en detalle cómo se debe pensar, o ser autónomo.

Lo expuesto anteriormente pone de manifiesto la trascendencia de las actividades realizadas durante el curso orientadas al desarrollo de la profesión docente, teniendo en cuenta el concepto de educación como medio destinado al desarrollo de la personalidad y el autoconocimiento como la vía de acceso en el proceso de conocerse a "sí mismos", en la construcción de la identidad profesional y en el desempeño reflexivo tan necesario de la profesión. De otro modo, la autoobservación constituye un elemento de cambio significativo en la percepción de autoeficacia (Iglesias y Galicia, 2018).

El interés de crecimiento y desarrollo profesional consciente, la responsabilidad de las actividades de formación de la visión del mundo de los estudiantes y los puntos de referencia del comportamiento a través de un prisma de valores humanos universales, el desarrollo de su necesidad de autoconocimiento y la atención integral son una propuesta que puede convertirse en la base de la formación psicológica y pedagógica de los futuros maestros y maestras. Por lo tanto, el más actual es el problema de la detección de los rasgos profesionales y personales que influyen en la preparación del futuro docente en la fase de formación en las instituciones de enseñanza superior.

Desarrollar estrategias pedagógicas que ayuden de esta forma a la consolidación de competencias reflexivas necesarias para el ejercicio de la profesión del ser del educador. El quehacer profesional de alumnos y profesores es susceptible de transformarse en vía de maduración interior, por medio de la práctica de la consciencia constante; de donde se deduce que los mejores profesores y alumnos posibles son aquellos que, desde su vía, la didáctica u otra más sencilla, alcanzan la maestría. El autoconocimiento es, por tanto, un proceso constante de acción sobre un efecto que conlleva al reconocimiento del sí mismo. 
Igualmente somos conscientes de los límites que tiene la experiencia de la cual pretendemos dar cuenta en este trabajo, pues los cambios anunciados se producen desde la experiencia de lo aprendido y la práctica en el trabajo cotidiano en una relación de praxis dialéctica.

\section{Referencias}

Ander-Egg, E. (1990). Repensando la investigación-acción-participativa. Buenos Aires: Lumen.

Aranda Pescador, C. (2013). Aproximación al origen del pensamiento de George Ivanovitch Gurdjieff: las raíces musulmanas. Tesis doctoral. Universidad Complutense de Madrid.

Ávila, J. (2015). Didáctica de la emoción: De la investigación al aula de ELE, marco ELE. Revista de Didáctica Español Lengua Extranjera, (21), 1-171.

Baudino, K.A. (2014). El eneagrama Sufi. Málaga, España: Ediciones Huwa.

Baudino, K.A. (2017). Ejercicios de psicología Sufi: Basado en las enseñanzas de Mawlana Sheikh Nazim, G.I. Gurdjieff y el Eneagrama. Málaga, España: Ediciones Huwa.

Bisquerra, R. y García Navarro, E. (2018). La educación emocional requiere formación del profesorado. Participación educativa. Revista del Consejo Escolar del Estado. Vol. 5, $n^{\circ}$ 8.

Boixadós, A., Munté \& Pascual, A., Zueras, V., Matulic Domandzic, M. V., y Báñez Tello, T. (2017). El autoconocimiento en el espacio de la supervisión educativa, en los estudios de trabajo social de la Universidad de Barcelona. XIV Symposium Internacional sobre el prácticum y las prácticas externas, Asociación para el Desarrollo del Prácticum y de las Prácticas Externas, Poio (Pontevedra: Red de Prácticum (REPPE). Poio (Pontevedra). Red de Prácticum.

Boletín Oficial del Estado. (2006, 4 de mayo). Ley Orgánica 2/2006, de 3 de mayo, de Educación, núm. 106, pp. 17158-17207. [consultado el 6 de noviembre de 2020]. Disponible en: http://www.boe.es/boe/dias/2006/05/04/pdfs/A17158-17207.pdf

Caballero, M. (2017). Neuroeducación de profesores y para profesores. De profesor a maestro de cabecera. Madrid: Pirámide.

Caparrós, E. y Sierra, J. E. (2019). Encender el deseo de saber. Movilizar las visiones epistemológicas en la formación inicial de maestras y maestros. Revista Interuniversitaria de Formación del Profesorado, 94 (33.3) 175-194.

Chernicoff Minsberg, L., \& Rodríguez Morales, E. (2018). Autoconocimiento: una mirada hacia nuestro universo interno. Didac, (72), 29-37.

De Dios Alija, T. (2020). Transformación de un modelo educativo a través de la formación y las comunidades docentes de aprendizaje. Revista Interuniversitaria de Formación del Profesorado, 95 (34.2) 61-78

Espinoza, E. I. J. (2015). Desarrollo personal y profesional de maestras de educación primaria: aportes de la orientación. Revista Electrónica Actualidades Investigativas en Educación, 15 (1), 1-29.

Etievan, N. (1996). No saber es formidable. Venezuela: Ganesha.

Fontana Abad, M., Robledo Poma, F. N., \& Juárez Pérez, G. (2011). Enfoque sistémico, eneagrama y coaching como un marco de metodología innovadora docente universitaria. VIII Jornadas Internacionales de Innovación Universitaria 
Retos y oportunidades del desarrollo de los nuevos títulos en educación superior. Madrid.

Gardner, H. (2020). A Synthesizing Mind: A memoir from the creator of multiple intelligences theory. United States: MIT Press Ltd.

Germer, C. K. (2017). El poder del mindfulness. Barcelona: Ediciones Paidós.

Goleman, D. (2018). Inteligencia emocional en la empresa (Imprescindibles). Barcelona: Conecta.

Goleman, D. (2010). La práctica de la inteligencia emocional. Barcelona: Editorial Kairós.

Iglesias, J. y Galicia, I. X. (2018). El impacto de la auto-observación en la autoeficacia del docente universitario. Revista interuniversitaria de formación del profesorado, $\mathrm{n}^{\circ}$ 93, $113-126$.

Lachman, G. (2016). Una historia secreta de la Consciencia. Girona: Atalanta.

Moscoso, M. S. (2019). Hacia una integración de mindfulness e inteligencia emocional en psicología y educación. Liberabit, 25(1), 107-117.

Naranjo, C. (2010). Carácter y Neurosis. Una Visión Integradora. Vitoria-Gasteiz: Ediciones La Llave.

Naranjo, C. (2010). El Eneagrama de la Sociedad. Males del Mundo, Males del Alma. VitoriaGasteiz: Ediciones La Llave.

Naranjo, C. (2017). 27 personajes en busca del Ser. Barcelona: La llave.

Ocaña, A. O. (2015). Neuroeducación: ¿cómo aprende el cerebro humano y cómo deberían enseñar los docentes? Colombia: Ediciones de la $U$.

Punset, E., \& Bisquerra, R. (2016). Universo de emociones. Valencia: PalauGea Comunicación S.L.

Santander, M. L., Gaeta, V. y Martínez-Otero, V. (2020). Impacto de la regulación emocional en el aula: Un estudio con profesores españoles. Revista Interuniversitaria de Formación del Profesorado, 95 (34.2), 225-246.

Santiago Martínez, M. P. (2010). Pedagogía transpersonal: una nueva realidad humana pide una nueva pedagogía. Qurriculum: Revista de teoría, investigación y práctica educativa, (23), 103-126.

Silva-Peña, I. y Paz-Maldonado, E. (2019). Formación docente para la justicia social desde la perspectiva emocional: Indagaciones narrativas en el contexto de la revolución del torniquete. Revista Interuniversitaria de Formación del Profesorado, 94 (33.3) 195-212.

Vidal, J. (2018). Una explicación del autoconocimiento psicológico. Tópicos, Revista de Filosofía, (54), 353-392.

Wilber, K. (2013). Los tres ojos del conocimiento. Barcelona: Kairós. 